\title{
ESPIRITUALIDADE, SAÚDE E CUIDADO HUMANIZADO EM AMBIENTE DE ENSINO: RELATO DE EXPERIÊNCIA
}

\author{
SPIRITUALITY, HEALTH AND HUMANIZED CARE IN THE \\ TEACHING ENVIRONMENT: EXPERIENCE REPORT
}

\author{
Larissa Lemos Silva ${ }^{1}$, Diéssica Roggia Piexak ${ }^{2}$, \\ Francine Carpes Ramos ${ }^{3}$ e Karoline do Pinho Martins ${ }^{4}$
}

\section{RESUMO}

Objetivo: descrever atividades de ensino sobre o reconhecimento da dimensão espiritual com estudantes de graduação em Enfermagem. Método: relato de experiência sobre o desenvolvimento de oito atividades que buscaram propiciar o reconhecimento da dimensão espiritual de 21 estudantes de graduação em Enfermagem de uma Universidade Federal do Sul do Brasil. Resultados: planejamento, elaboração e realização de oito atividades que proporcionaram o reconhecimento da dimensão espiritual para a maioria dos estudantes, auxiliando na promoção de um cuidado humanizado. Conclusão: atividades como essas oportunizam aos estudantes o reconhecimento de dimensões para além do físico e fortalecem o cuidado humanizado imprescindível para os ambientes de ensino e saúde.

Palavras-chave: Enfermagem; Ensino; Estudantes; Espiritualidade; Saúde.

\section{ABSTRACT}

Objective: to describe teaching activities on the recognition of the spiritual dimension with undergraduate students in nursing. Method: A report of experience on the development of eight activities that sought to promote the recognition of the spiritual dimension of 21 undergraduate Nursing students from a Federal University in the south of Brazil. Results: planning, elaboration and accomplishment of eight activities that provided the recognition of the spiritual dimension for the majority of the students, helping in the promotion of humanized care. Conclusion: activities like these allow students to recognize dimensions beyond the physical and strengthen the humanized care which is essential to the teaching and health environments.

Keywords: Nursing, Teaching, Students, Spirituality, Health.

\footnotetext{
${ }^{1}$ Enfermeira. Especialização em andamento em Terapia Intensiva e Nefrologia. Atua na Clínica de Nefrologia e Diálise da cidade do Rio Grande. E-mail: larissalemos.s@hotmail.com

${ }^{2}$ Enfermeira. Doutora em Enfermagem. Professora Adjunta do curso de Graduação em Enfermagem e do Programa de Pós-Graduação em Enfermagem da Universidade Federal do Rio Grande - FURG. Coordenadora de Acompanhamento à Pós-Graduação (CAPG/PROPESP). E-mail: diessicap@yahoo.com.br

${ }^{3}$ Enfermeira. Residente no Programa de Residência Integrada Multidisciplinar em Saúde com ênfase na Atenção em Alta Complexidade de Saúde pela Universidade Federal de Santa Catarina - UFSC/HU. E-mail: franrammos@hotmail.com

${ }^{4}$ Acadêmica do curso de Graduação em Enfermagem da Universidade Federal do Rio Grande. E-mail: martinskaroline2@, gmail.com
} 


\section{INTRODUÇÃO}

Frequentemente, percebe-se uma fragmentação da assistência e esta traz, muitas vezes, efeitos negativos tanto para quem recebe quanto para quem fornece. Dessa forma, considera-se necessário que os profissionais de saúde compreendam a importância da integralidade da assistência/cuidado e da complexidade do ser humano para que assim consigam ressignificar os modelos assistenciais atuais e implementem o cuidado integral, valorizando igualmente todos os seus aspectos, sejam eles biológicos, psicológicos, sociais ou espirituais. Pensar no ser humano como um todo indissociável é também considerá-lo como espiritual, ou seja, considerar a dimensão da espiritualidade(ORO, 2011).

Para compreender a espiritualidade na perspectiva do cuidado integral em saúde, é preciso diferenciar o seu conceito do viés da religião e da religiosidade. A religião pode ser entendida como a crença na existência de um poder sobrenatural, criador e controlador do Universo, dando ao homem uma natureza espiritual que continua a existir depois da morte do corpo. A religiosidade, por sua vez, é o seguimento que um indivíduo acredita e segue a prática de uma religião. Já a espiritualidade está ligada à busca pelo significado da vida e à razão de viver, não limitada a tipos de crenças ou práticas religiosas (PANZINI et al., 2007).

A produção científica relacionada à temática da espiritualidade vem crescendo constantemente nos últimos anos (DAL-FARRA; GEREMIA, 2010), permitindo o desenvolvimento de novas estratégias para o cuidado em saúde e enfatizando a necessidade do atendimento a todas as dimensões que constituem o indivíduo, com ênfase no cuidado, tendo em vista que o ser humano é composto pela tríade mente/corpo/espírito.

Algumas pesquisas já foram realizadas dentro dos ambientes de ensino/aprendizagem, evidenciando que os estudantes de graduação em Enfermagem acreditam na influência da espiritualidade na saúde, mas, em contrapartida, consideram-se despreparados para abordar aspectos espirituais dos pacientes e possuem carência de discernimento entre religião, religiosidade e espiritualidade(ESPINHA et al., 2013).

Identifica-se, portanto, que a espiritualidade é vista atualmente como um elemento imprescindível para ser saudável (LIMA, 2013), o que torna necessário cuidar da dimensão espiritual como se cuida do corpo físico e/ou mental. Torna-se evidente que para prestar um cuidado espiritual e humanizado é necessário que os estudantes de Enfermagem e, consequentemente, futuros profissionais de saúde estejam instrumentalizados e tenham algumas habilidades desenvolvidas nesse sentido, sendo importante que as instituições de ensino superior disponham de ambientes propícios para a qualificação daqueles.

Partindo desse pressuposto, surgem as questões norteadoras do estudo: como promover o reconhecimento da dimensão espiritual do estudante de enfermagem? Como o reconhecimento da dimensão espiritual do estudante poderá auxiliar no cuidado humanizado? Dessa forma, objetiva-se descrever atividades de ensino sobre o reconhecimento da dimensão espiritual com estudantes de graduação em Enfermagem. 


\section{MÉTODO}

Relato de experiência sobre o desenvolvimento de oito atividades que buscaram propiciar o reconhecimento da dimensão espiritual de 21 estudantes de graduação em Enfermagem de uma Universidade Federal do Sul do Brasil. Essas atividades foram realizadas na Escola de Enfermagem da Universidade Federal do Rio Grande (FURG), situada no campus Saúde, na cidade do Rio Grande. Todos os estudantes do curso de graduação em Enfermagem da referida universidade foram convidados para participarem. Houve 30 inscrições, porém compareceram 20 estudantes nas atividades desenvolvidas pelo turno da manhã e 1 a mais (21) nas atividades desenvolvidas pelo turno da tarde.

O convite para participar das atividades foi divulgado por meio da internet e de cartazes nos murais da área acadêmica. As inscrições foram realizadas via e-mail específico. As atividades aconteceram no dia 2 de setembro de 2017, das 08 h30 às 12h e 13 h30 às 17h30. Para organização, divulgação e realização das atividades, contou-se com a participação da professora coordenadora, uma estudante do curso de graduação em Enfermagem e uma enfermeira egressa da mesma instituição, autoras deste relato. Os certificados foram enviados para os participantes via e-mail.

Para atingir o objetivo, realizaram-se oito atividades que propiciaram, de diferentes formas, a aproximação da temática espiritualidade no contexto da saúde e o reconhecimento da dimensão espiritual. No turno da manhã ocorreram cinco atividades; após, oportunizou-se um intervalo de 1 hora e meia para almoço e no turno da tarde outras três atividades foram desenvolvidas.

\section{RESULTADOS}

Os resultados obtidos foram o planejamento, a elaboração e realização das oito atividades propostas. A primeira atividade foi a meditação, que durou aproximadamente 10 minutos e possuía como objetivos acalmar os pensamentos e focar a atenção dos participantes para o momento presente. Vale ressaltar que a meditação pode ser definida como uma prática que possui um conjunto de técnicas que buscam treinar a focalização da atenção (SHAPIRO, 1981). Os estudantes se acomodaram nas cadeiras e no chão, de acordo com a sua preferência, e, de olhos fechados, concentraram-se na meditação guiada que estava sendo tocada ao fundo. A meditação utilizada foi elaborada pela professora coordenadora e por outra professora da FURG que atuam nessa área.

A aplicação de escalas foi a segunda atividade, com duração aproximada de 15 minutos. Após a concentração inicial descrita, as duas escalas foram entregues aos participantes para que preenchessem conforme a sua percepção aspectos relacionados à religiosidade e espiritualidade. As duas foram lidas e explicadas brevemente e eles marcaram as opções que consideraram mais adequadas. Compreendendo que para fornecer um cuidado espiritual humanizado é necessário possuir um considerável autoconhecimento referente àquilo que se sente e se pensa em relação à sua religiosidade e 
espiritualidade, a aplicação das escalas de Espiritualidade de Pinto C \& Pais-Ribeiro e o Índice de Religiosidade da Universidade Duke tornaram-se essenciais para identificar como os estudantes de enfermagem visualizam essas características.

A terceira atividade foi uma roda de conversa sobre os conceitos dos participantes acerca da temática trabalhada, que durou aproximadamente 1 hora. Iniciou-se a conversa com o seguinte questionamento: “Qual a sua percepção sobre religião, religiosidade, espiritualidade e humanização?”, deixando o espaço aberto para que os participantes falassem livremente sobre o que pensavam, se diferenciavam os conceitos de religiosidade e espiritualidade e se possuíam alguma correlação entre a utilização da espiritualidade no contexto da saúde.

Em seguida, realizaram-se a confecção e pintura de mandalas, como quarta atividade, durando cerca de 30 minutos. A palavra mandala provém do sânscrito e significa "círculo" e é considerada como sendo a imagem e o motor da ascensão espiritual, que surge a partir de uma interiorização cada vez mais elevada da vida (CHEVALIER; GHEERBRANT, 2001). Após esclarecimento desses itens teóricos, alguns participantes confeccionaram e outros pintaram as mandalas, buscando a ligação com o espiritual, com a finalidade de interiorizarem-se.

A dinâmica do corredor do amor foi a quinta atividade e encerrou o turno da manhã. Durou cerca de 20 minutos e todos os estudantes demonstraram intenso apreço durante e após a realização da mesma. Essa atividade objetivou promover o reconhecimento da dimensão espiritual por meio da vivência de coragem ao fechar os olhos, de confiança ao dar os passos no corredor do amor e estímulo a pensamentos e palavras positivas ao expressar o sentimento dos estudantes. $\mathrm{O}$ corredor foi formado pelos estudantes participantes e um de cada vez passava por ele. No momento em que o estudante passava no corredor com os olhos fechados, os demais estudantes falavam palavras e/ou frases de estímulo no seu ouvido. Foi um momento de muita emoção e de exacerbação de diversos sentimentos positivos, expressos por meio do choro, de risos e de demonstrações de afeto e carinho. Durante essa atividade, utilizou-se música relaxante ao fundo.

A sexta atividade, que iniciou o turno da tarde, foi a exposição da apresentação em mídia digital (PowerPoint), que durou cerca de uma hora. Os 21 slides apresentados foram construídos com a revisão de literatura feita previamente. A atividade objetivou realizar o aprofundamento teórico acerca da temática de espiritualidade e saúde, permitindo que todos os conceitos anteriormente discutidos possuíssem um maior esclarecimento.

A sétima atividade realizada foi a resposta a dois questionamentos expostos ao fim da apresentação teórica: "como você praticaria o cuidado espiritual?" e "como você gostaria que esse cuidado fosse realizado?".

A oitava atividade, que finalizou o dia, foi o preenchimento do instrumento de avaliação que durou cerca de 10 minutos. O objetivo foi conhecer as percepções dos estudantes acerca das atividades realizadas. Os resultados obtidos por meio dessas fichas demonstram que a maioria dos 
estudantes considerou que as atividades propostas atingiram seus objetivos, que o reconhecimento da sua dimensão espiritual se torna essencial para praticar um cuidado em saúde mais humanizado e que atividades de ensino, como as que foram propostas, devem ser replicadas para que mais pessoas tenham acesso a essa visão multidimensional do ser humano e se instrumentalizem, com a reflexão e autoconhecimento, para praticar o cuidado espiritual humanizado.

\section{DISCUSSÃO}

Compreende-se que a universidade é um espaço onde atividades de ensino, pesquisa e extensão devem ser realizadas de forma complementar e interdependente, o que forma um ciclo dinâmico e interativo, no qual a pesquisa produz novos conhecimentos, os quais são difundidos por meio do ensino e da extensão (PIVETTA et al., 2010). Nessa perspectiva, enfatiza-se que as ações de ensino não devem se restringir à sala de aula, mas também precisam ser ampliadas por meio de projetos e ações que envolvam os estudantes a fim de que os mesmos se aprofundem em diversas temáticas e possuam a instrumentalização necessária para a futura prática profissional.

Parte-se do pressuposto que a função do profissional de saúde é aliviar as dores humanas, sendo de sua responsabilidade adquirir autocontrole para que tenha serenidade em lidar com o sofrimento dos pacientes. Assim, o desenvolvimento espiritual, representado pela busca constante por autoconhecimento e automelhoramento, é imprescindível para o encontro da liberdade e equilíbrio emocional para tratar bem aqueles que sofrem (AGUIAR, 2013).

Compreendendo que a ciência está se voltando para o estudo da espiritualidade, esta manifestando-se como essência do ser e a saúde sendo produzida como resultado do conhecimento da espiritualidade e seu desenvolvimento harmônico (LIMA, 2013), encontra-se a possibilidade de criação de ambientes propícios para integração do cuidado espiritual às demais dimensões humanas dentro das instituições de saúde.

Diversos estudos vêm sendo realizados e demonstram a necessidade de realizar atividades que trabalhem a temática da espiritualidade nos ambientes de ensino. Ilustrando essa afirmação, um estudo realizado com 30 enfermeiros, em um hospital de São Paulo, evidenciou que a maioria deles referiu não ter recebido uma formação profissional para prestar uma assistência espiritual ao paciente em nenhum dos cursos de Enfermagem que realizaram, o que comprova a necessidade de que nos cursos de formação profissional e/ou de educação continuada se amplie o espaço de reflexão e discussão acerca da espiritualidade e da assistência espiritual ao paciente (PEDRÃO; BERESIN, 2010).

Considerando, ainda, os resultados obtidos nas fichas avaliativas, nas quais a maioria dos estudantes pontuou que as atividades realizadas os aproximaram da temática e os fizeram reconhecer sua própria dimensão espiritual, há estudos (ESPINHA et al., 2013; LIMA, 2013) que pontuam a necessidade da implementação de cenários de aprendizagem durante a graduação para que os discentes 
desenvolvam a competência de realizar um cuidado espiritual. Ainda, enfatiza-se que essa temática precisa ser discutida formalmente no ensino da graduação, uma vez que o objeto do ensino da Enfermagem é o ser humano, sendo necessário ter a compreensão do mesmo como um ser bio/psico/sócio/ espiritual (BENKO; SILVA, 1996). Dessa forma, as colocações dos estudantes quanto à realização desse tipo de atividades vão de encontro com as necessidades supracitadas, tornando-as fundamental para a formação do profissional enfermeiro.

Estudo evidenciou que os docentes e estudantes de enfermagem acreditam que a espiritualidade influencia muito na saúde do paciente e que estes sentiam vontade de abordar o assunto, porém poucos julgavam-se preparados para tal, sendo que a maioria acreditava que a universidade não proporcionava informações necessárias sobre o tema (TOMASSO; BELTRAME; LUCCHETTI, 2011).

Entende-se que não deverá existir uma "fórmula" pronta para propiciar o reconhecimento espiritual do estudante de enfermagem e/ou do paciente que está sob seus cuidados. Todavia, acredita-se que inúmeras atividades, como essas realizadas, podem aproximar cada vez mais os estudantes da sua essência espiritual e assim auxiliá-los ao encontro da sua sensibilidade para posteriormente perceber a necessidade espiritual do seu paciente, humanizando em saúde.

\section{CONCLUSÃO}

Compreender e reconhecer a espiritualidade como pertencente à multidimensionalidade humana é um passo primordial para implementar um cuidado integral e humanizado. Partindo do princípio que os ambientes acadêmicos devem proporcionar a base para que os futuros profissionais saibam intervir em todas as vertentes, o presente trabalho teve como objetivo o desenvolvimento de atividades de ensino que propiciassem o reconhecimento da dimensão espiritual de estudantes para que vivenciassem como o cuidado espiritual pode auxiliar na promoção de um cuidado humanizado.

As atividades oportunizaram a aproximação dos estudantes com a temática da espiritualidade e saúde, sensibilizando-os quanto à necessidade de um olhar mais ampliado para si mesmo. A maioria dos estudantes identificou que o reconhecimento da dimensão espiritual auxilia na promoção de um cuidado humanizado, demonstrando que a instrumentalização e aproximação com o tema são necessárias durante o processo de formação.

Espera-se que o desenvolvimento dessas atividades tenha sido o primeiro passo para a integração da temática no ensino da Enfermagem e que todos os participantes tenham sido minimamente tocados quanto à necessidade de considerar a dimensão espiritual em todas as pessoas e ambientes. Todas as atividades realizadas, a emoção aflorada e os sentimentos despertados serão para sempre relembrados com um sentimento de gratidão e dever cumprido. Todos nós temos nosso próprio tempo 
de evolução, mas devemos plantar as sementes do amor e do conhecimento a todo o momento para que a colheita ocorra quando estivermos preparados.

\section{REFERÊNCIAS}

AGUIAR, L.S.F. Uma proposta para a espiritualidade na formação médica. In: SALGADO, M.I.; FREIRE, G. Saúde e Espiritualidade - Uma nova visão da Medicina. São Paulo: Editora Inede, 2013. p. 31-42.

BENKO, M.A.; SILVA, M.J.P. Pensando a espiritualidade no ensino de graduação. Revista Latino-America de Enfermagem, Ribeirão Preto, v. 4, n. 1, p. 71-85, 1996.

CHEVALIER, J.; GHEERBRANT, A. Dicionários de símbolos. Rio de Janeiro: José Olympio, 2001.

DAL-FARRA, R.A.; Geremia, C. Educação em Saúde e Espiritualidade: Proposições Metodológicas. Revista Brasileira de Educação Médica, Rio de Janeiro, v. 34, n. 4, p. 587-597, 2010.

ESPINHA, D.C.M. et al. Opinião dos estudantes de enfermagem sobre saúde, espiritualidade e religiosidade. Revista Gaúcha de Enfermagem, Porto Alegre, v. 34, n. 4, p. 98-106, 2013.

LIMA, M.C.A. Quântica: Espiritualidade e Saúde. 2. ed. Porto Alegre: AGE Editora, 2013.

ORO, J. O cuidado integral de enfermagem em unidade de internação hospitalar. 163 p. (Dissertação de mestrado: gestão do cuidado em enfermagem) - Universidade Federal de Santa Catarina, Santa Catarina, 2011.

PANZINI, R.G. et al. Qualidade de vida e espiritualidade. Revista de Psiquiatria Clínica, São Paulo, v. 34, p. 105-115, 2007.

PEDRÃO, R.B.; BERESIN, R. O enfermeiro frente à questão da espiritualidade. Einstein (São Paulo), São Paulo, v. 8, n. 1, p. 86-91, 2010.

PIVETTA, H.M.F. et al. Ensino, pesquisa e extensão universitária: em busca de uma integração efetiva. Revista Linhas Críticas, [s.1.], v. 16, n. 31, p. 377-390, 2010. 
SHAPIRO, D. Meditation: Clinical and health-related applications. The Western Journal of Medicine, [s.1.], v. 134, n. 2, p. 141-142,1981.

TOMASSO, C.S.; BELTRAME, I.L.; LUCCHETTI, G. Conhecimentos e atitudes de docentes e alunos em enfermagem na interface espiritualidade, religiosidade e saúde. Revista Latino-Americana de Enfermagem, São Paulo, v. 19, n. 5, p. 1205-1213, 2011. 